\title{
Toward a New Enterprise: Capitalizing on the Faculty-Librarian Partnership
}

\section{Ada M. Ducas and Nicole Michaud-Oystryk}

\begin{abstract}
In spring 2000, the authors undertook a study to explore the interaction between academic librarians and faculty at the University of Manitoba, the impact of librarians' contributions, and the future roles of librarians. The following five areas were investigated: teaching/instruction, information services, information technology, research, and collections. The results clearly show that when faculty interact with librarians, librarians have a very positive and considerable impact on both faculty and students. In addition, the faculty responses indicate that they are receptive to collaborating with librarians at a higher level of interaction than currently experienced.
\end{abstract}

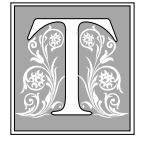

his research project is a quasi follow-up to a study the authors conducted in 1985 and reported in the article, "Faculty Perceptions of Librarians at the University of Manitoba." ${ }^{11}$ In that study, "librarians were seen as 'professionals' with a 'service' function. Activities such as research, teaching, and management received low ratings. The results indicated a low acceptance of librarians as fullfledged academic colleagues in the University of Manitoba setting."2

Fifteen years later, the authors wished to investigate whether there had been any changes but wanted to go beyond a study of perceptions and observations. Therefore, a study was designed to explore:

- the current role that librarians are playing in collaboration with faculty;
- the impact of the librarians' contribution to the academic enterprise;

- the future roles of librarians that may enhance the librarian-faculty partnership.

The librarian-faculty partnership was examined in the following five areas: teaching/instruction, information services, information technology, research, and collections.

Today, major paradigm shifts in the delivery of information are the driving force behind the changing roles and responsibilities of academic librarians. The proliferation of information in many different formats, the transition from paper to electronic media, and the advent of technological innovations suggest that librarians are playing - and will continue to play - a critical role in the evaluation,

\footnotetext{
Ada M. Ducas is Head of the Neil John Maclean Health Sciences Library at the University of Manitoba; email: ada_ducas@umanitoba.ca. Nicole Michaud-Oystryk is Head of the Elizabeth Dafoe Library at the University of Manitoba; e-mail: nicole_michaud-oystryk@umanitoba.ca. The authors would like to acknowledge the Social Sciences and Humanities Research Council of Canada and the University of Manitoba for the SSHRC/UM Research Grant, the University of Manitoba Libraries for financial and research support, and Dr. D. Murphy, Statistical Advisory Service, University of Manitoba, for statistical support.
} 
analysis, and filtering of information. A survey of the recent library literature challenges librarians to rethink their role and to build relationships with faculty in order to become more active partners in the educational process. In a key article, Sheila D. Creth stressed the need for librarians to redefine and expand their role in the areas of instruction, information and scholarly process, knowledge management, and organization of networked information resources. She also discussed the importance of librarians as an integral part of the institution and the user

A survey of the recent library
literature challenges librarians
rethink their role build
relationships with faculty
become more active the
educational process.

community they serve. ${ }^{3}$ In their article, Carla Stoffle, Barbara Allen, and Janet Fore set strategies for meeting the challenges: "To successfully compete, we must leverage our resources, redirect our priorities, collaborate, take risks, and reinvent our organizations. Within our institutions we must move to the beginning of the learning and knowledge creation processes becoming partners with the faculty." ${ }^{4}$ Recognizing progress on that front, Doug Cook has stated that the paradigm shifts have "forced librarians to rethink their role in academia" and that as a result "connections have been created between the library and the rest of the campus." 5

Although numerous publications have discussed the collaboration between librarians and faculty in specific areas of responsibility, the authors identified only a small number of studies published in the past decade that report survey data, and in that sense, relate to this study. Mary Lynn Rice-Lively and J. Drew Racine conducted a case study at a large research library to gather perceptions and observations about the changing role of librarians from the perspective of students, library and information sciences faculty, and academic librarians. ${ }^{6}$ A noteworthy article by Evan St. Lifer reported on a survey that aimed to determine to what degree librarians' jobs are changing and why. ${ }^{7}$ Other studies include the following: Donald H. Dilmore examined the librarian-faculty interaction at nine small colleges and the relationship between the interaction and faculty perceptions and use of library services; Devin Feldman and Susan Sciammarella surveyed teaching faculty at six community colleges to understand their perceptions of librarians and librarianship; Bee Gallegos and Thomas Wright reported the results of a survey posted on electronic discussion lists dealing with types of projects librarians and faculty pursued in collaboration; and Anita Cannon surveyed the faculty's general attitudes and practices on library research instruction in the humanities and social sciences department at York University. ${ }^{8-11}$

The present study conducted at the University of Manitoba aims to supplement this body of literature by examining and evaluating the current collaboration between faculty and librarians and by outlining a new and expanded role for librarians in partnership with the faculty.

\section{Methodology}

The basis of the study was a survey developed by the authors and sent to all 1,400 full-time faculty at the University of Manitoba in March 2000. The survey was an attempt at a census, and therefore the results are representative only of those who responded. The questionnaires were coded to facilitate two follow-up mailings to nonrespondents. Faculty members were assured that the replies would be confidential and that the study had been reviewed and approved by the university's Faculty of Arts Ethics Review Committee. The R statistical software was used to compute the results. ${ }^{12}$

The results cited in this paper are to be viewed as descriptive in nature. In particular, chi-square tests are used to compare three different faculty groups (see Profile of Respondents below). In these 


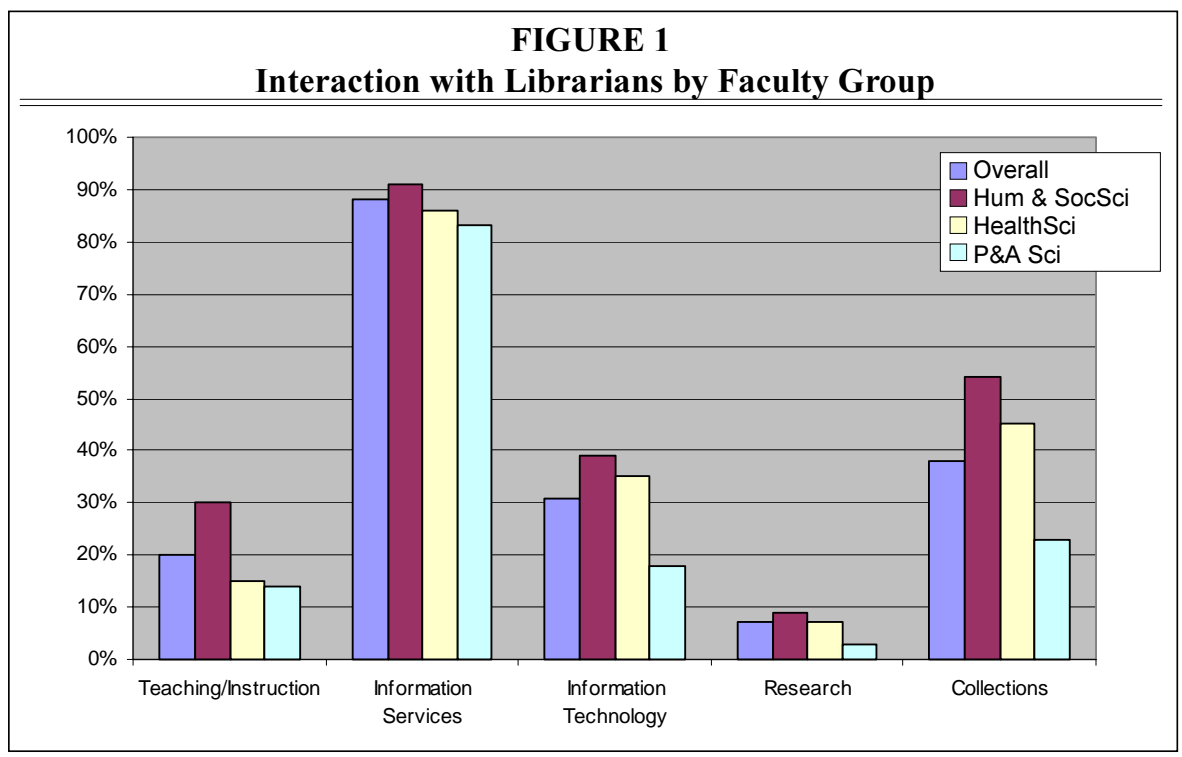

tests, the null hypothesis of interest will always be that the proportion responding positively to the question at hand is equal across the three groups whereas the alternative hypothesis is that at least two of the groups respond differently. Each of the five sections of the questionnaire has a preliminary question that yields a yes or no response. The remaining followup questions within a section, except for the impact question, allow multiple responses to the various options. For such questions, comparisons among faculty groups are not independent from option to option. As a result, a Bonferroni-like adjustment to the $p$-values is applied that depends on the number of choices to a given question. Essentially, this adjustment requires a $p$-value smaller than the significance level (e.g., 0.05) divided by the number of choices to a multiple-response question. For example, if there are six choices, the $p$-value must be smaller than $0.05 / 6$ before significance is declared. This action produces a conservative criterion for declaring statistical significance among groups.

It is important to note that the chisquare test assumes that the subjects constitute a random sample, which is clearly violated in this study. Hence, any signifi- cant results declared are to be interpreted as representative only of the responding faculty members at the University of Manitoba.

\section{Survey Instrument}

The survey, an eight-page questionnaire, required respondents to indicate the following:

- whether they had interacted with librarians in the five areas of investigation (if they had not interacted, what were their reasons; if they had, what was the type of interaction);

- whether the interaction had an impact on their work or their students' performance (if yes, the type of impact; if not, why not);

- other ways librarians could contribute;

- the importance of the librarians' role in the university.

For the most part, the questions were close-ended; the researchers provided what they considered to be the most probable choices and invited respondents to check as many as applied. Respondents also were given the opportunity to provide additional possibilities in an "other" category and to provide general comments at the end. 


\section{Profile of Respondents}

The final number of usable responses was 734 , or 52 percent of the target population surveyed. Faculty were asked to indicate their affiliation with one of twenty faculties/schools. Because the number of respondents from some faculties/schools was small, the units were amalgamated into three broad faculty groups. Twelve respondents did not identify themselves with any faculty or school. Below is the percentage distribution of those who did:

- Humanities and Social Sciences, 36 percent $(n=261)$

- Health Sciences, 42 percent $(n=311)$

- Pure and Applied Sciences, 20 percent $(n=150)$

\section{Interaction and Collaboration}

The first part of the survey was designed to determine the level of interaction and collaboration between faculty and librarians. For each area of investigation, the survey asked faculty to report the type of interaction they had with librarians. If there had been no interaction, they were asked to state their reasons. Figure 1 illustrates the overall responses for each area of investigation and the responses by faculty group.

\section{Teaching/Instruction}

Twenty percent, or 150, of all the respondents answered in the affirmative to the preliminary question: Have you had a librarian teach a component of your course(s) or provide library instruction for your course(s)? Compared with the other two faculty groups, twice as many of the humanities \& social sciences respondents indicated that they had asked a librarian to teach a component of their course or provide library instruction $(p<.0001)$. (See table 1.)

When asked what type of interaction had occurred, the respondents who answered yes to the preliminary question reported that training for BISON/ NETDOC (BISON is the University of Manitoba's online public catalogue; NETDOC is an in-house aggregation of networked databases) and that database searching was requested more than twice as often as other types of instruction. These results were not unexpected because this type of instruction has been most common at the university. Design and evaluation of library assignments were requested by only 11 percent. This is an area where librarians need to be more proactive in marketing their skills. Librarians know that library instruction is most effective when combined with an assignment whereas faculty may not value this type of instruction. Accounting for 37 percent of the results, the humanities \& social sciences faculty were most likely to request instruction in research methods $(p=.0096)$.

A very high percentage of the faculty responded that no interaction with librarians had occurred (578, or 79\%). Almost half these respondents deemed it inappropriate to ask a librarian to teach a component of their course or to provide library instruction, and 28 percent responded that they were unaware that librarians provided this service, once again underlining the need for librarians to market their skills. Over one-quarter chose the "other" category. Some of the reasons cited by faculty included: no teaching responsibilities; only one- or two-hour sessions taught; students expected to know the information in advanced classes; faculty not located on campus.

There was a large discrepancy in the results by the faculty group, with 58 percent of the pure \& applied sciences group answering that they considered it inappropriate for librarians to teach or provide library instruction, as opposed to 43 percent from the humanities \& social sciences and 38 percent from the health sciences $(p=$ .0018). Similarly, although the librarians' background or expertise was not a major factor in the faculty's decision not to request instruction, the pure \& applied sciences faculty were more than twice as likely to consider that librarians had insufficient ability or expertise $(p=.0044)$.

\section{Information Services}

The next area of investigation was infor- 


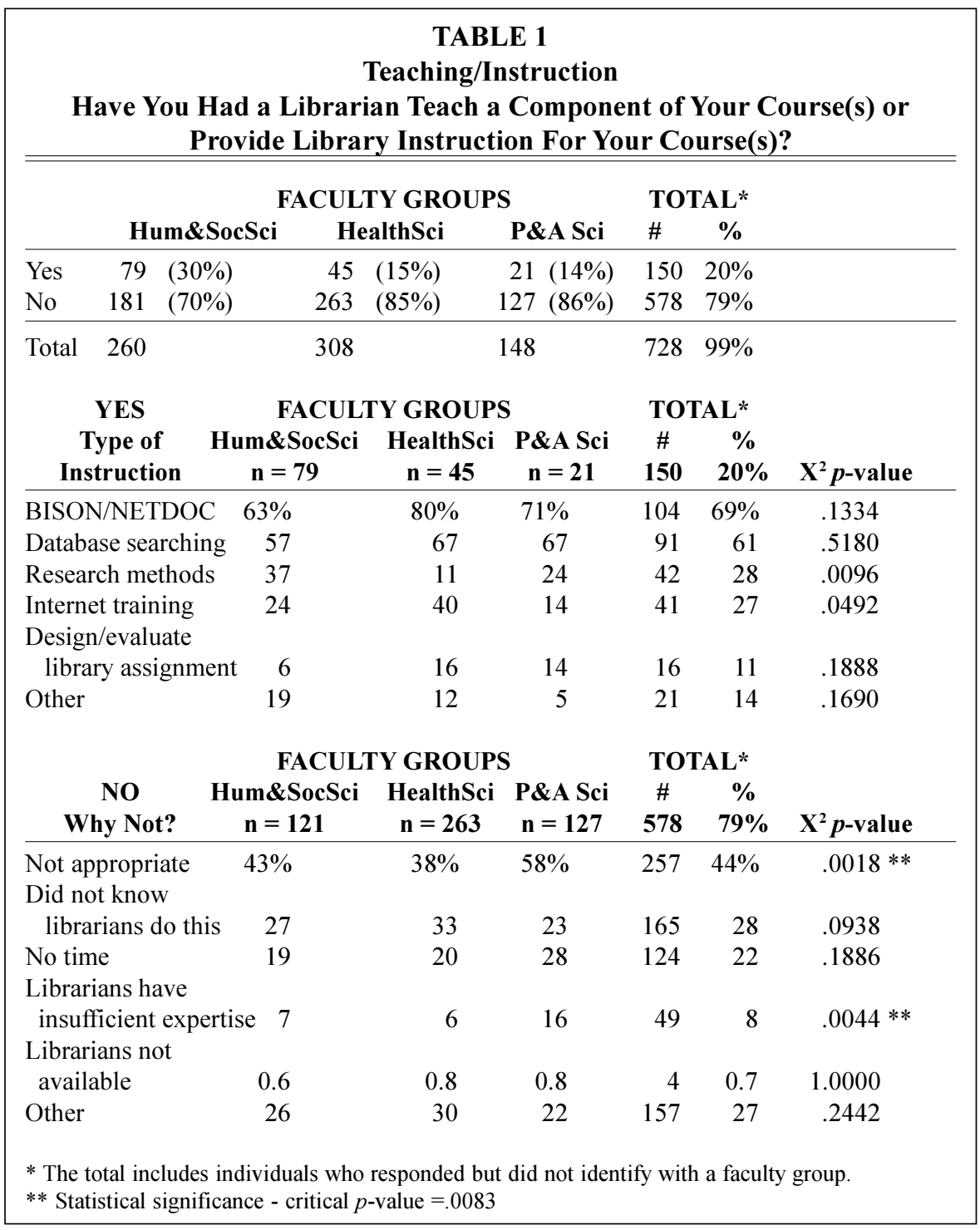

mation services. As expected, responses to the preliminary question, Have you ever requested assistance from librarians in finding information? yielded the highest response rate to faculty-librarian interaction. Eighty-eight percent or 642 of the 734 respondents answered that they had requested assistance from librarians (table 2). With a response rate of 83 percent, the pure \& applied sciences faculty requested assistance significantly less often than the humanities \& social sciences faculty did at 91 percent $(p=.034)$.
Of the total affirmative responses to the preliminary question, using BISON/ NETDOC, seeking information about library services, conducting a literature search, and tracking down citations received similar results, ranging between 44 and 55 percent. Faculty were least likely to ask librarians for help in searching pedagogical materials. It may be that faculty have all the pedagogical materials in their area, do not require them, or already know where to find them. Tracking citations received similar response 
rates from the health sciences and the pure \& applied sciences faculties, 50 and 49 percent respectively, as opposed to the humanities \& social sciences faculty with a much lower 37 percent rate $(p=.0052)$. This might be attributed to the fact that in the sciences, access to the most recent research is vital to clinical practice and research activities whereas in the humanities recent literature adds to the body of knowledge but does not necessarily supersede earlier publications. The pure \&

\section{TABLE 2}

Information Services

Have You Ever Requested Assistance from Librarians in Finding Information?

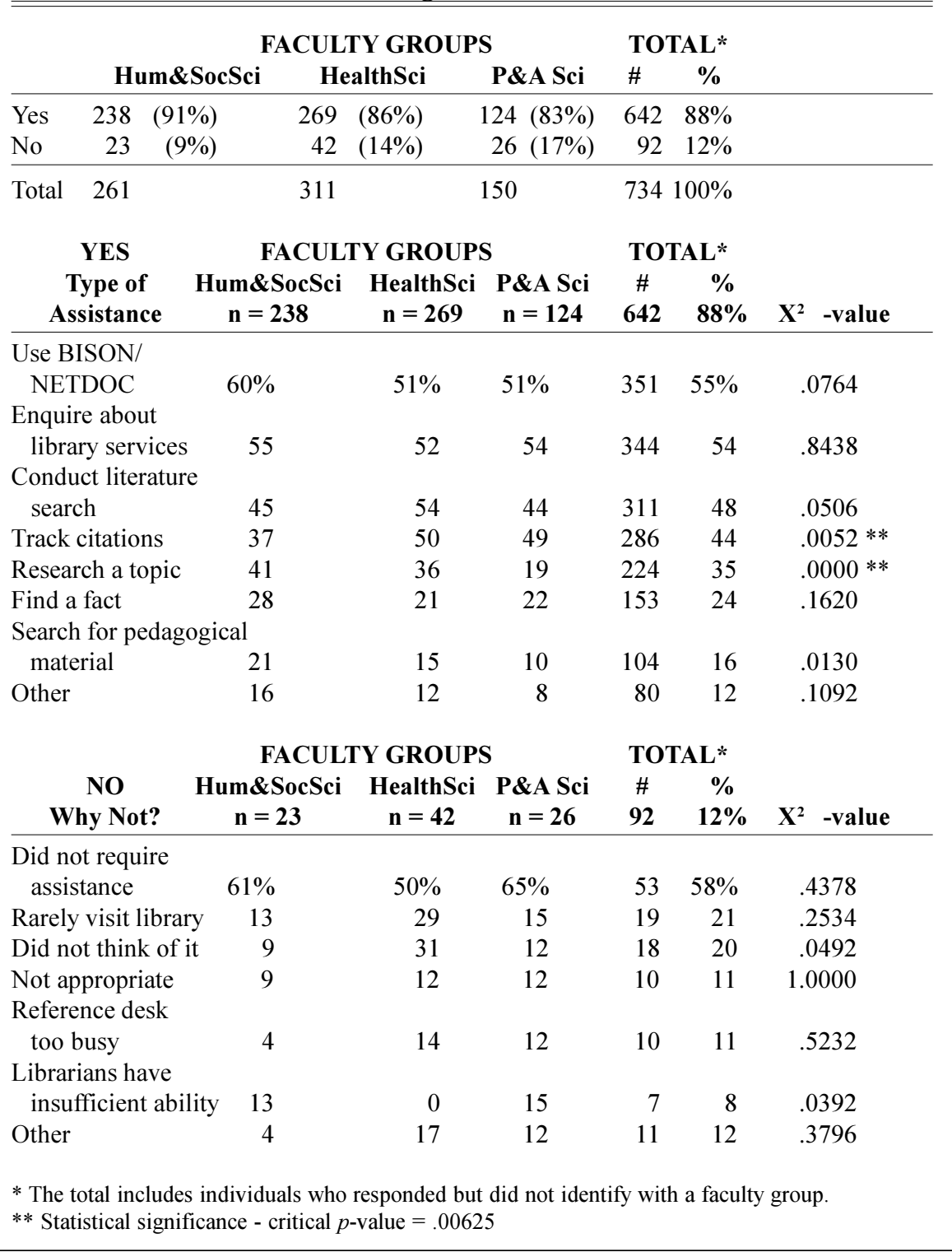




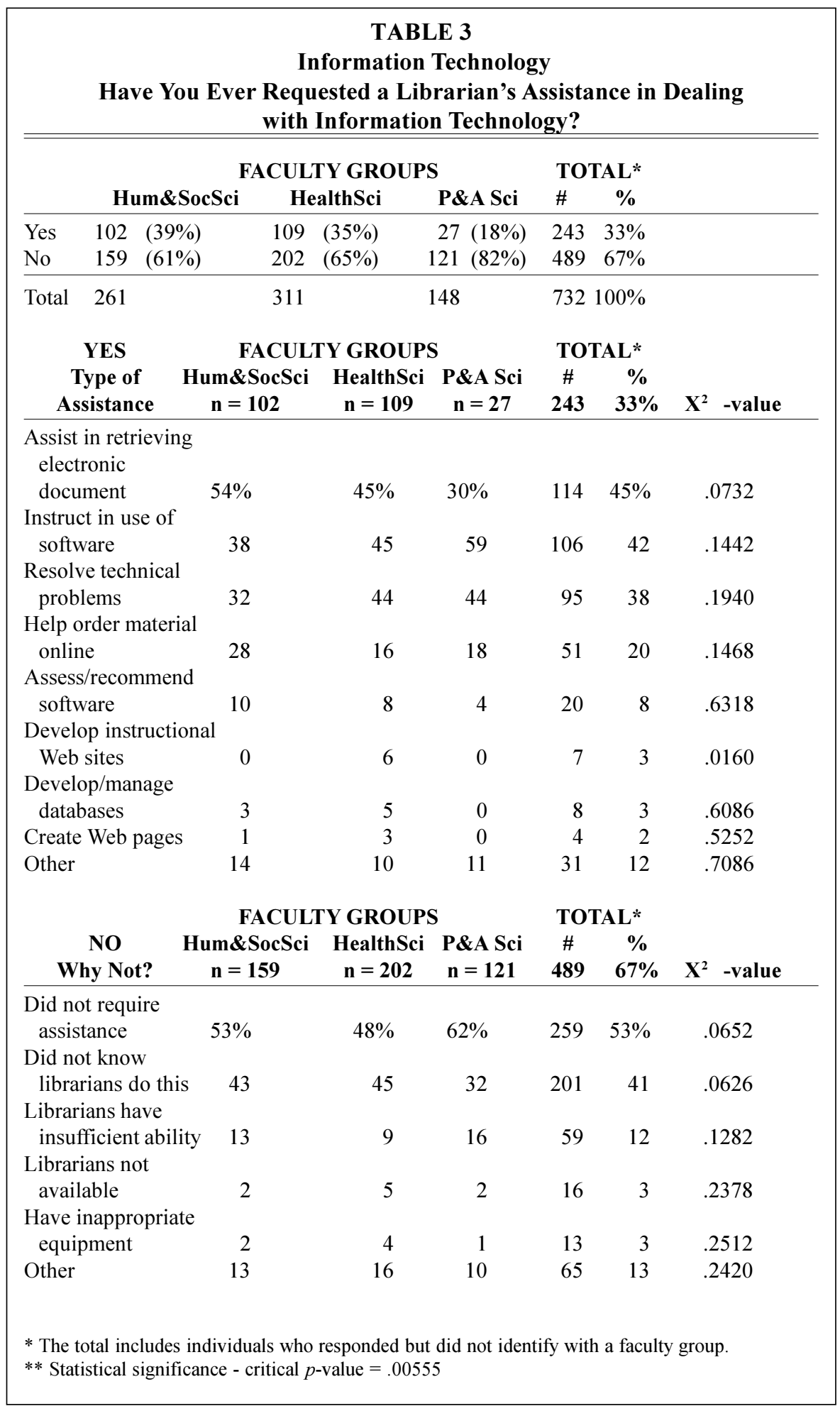


applied sciences faculty, with a response rate of 19 percent, were least likely to ask for help in researching a topic whereas the health sciences faculty did so at a rate of 36 percent and the humanities \& social sciences faculty at a rate of 41 percent $(p$ $<.0001$ ).

Of the ninety-two faculty members (12\% of 734$)$ who answered that they never requested assistance from librarians, 58 percent stated that they did not require assistance, 21 percent rarely visited the library, and 20 percent responded that they did not think of it. Only 8 percent maintained that librarians did not have sufficient ability or expertise.

\section{Information Technology}

The level of interaction in the area of information technology was determined by the responses to the preliminary question, Have you ever requested a librarian's assistance in dealing with information technology? Only 243 respondents (33\%) declared that they had (table 3 ). The pure \& applied sciences faculty were less likely to ask for assistance; only 18 percent reported that they had required assistance, compared to 35 percent for the health sciences faculty and 39 percent for the humanities \& social sciences faculty $(p<.0001)$.

When analyzing the results, the predominant types of assistance requested were technical in nature whereas the more creative and intellectual activities (i.e., creating Web pages, developing instructional Web sites, and developing and managing databases) received extremely low responses. Perhaps many faculty have not yet undertaken this latter set of activities or have other outlets. Librarians have developed expertise in these areas and could seize this opportunity to collaborate with faculty. Comments addressing additional types of assistance were cited in the "other" category: instruction in using electronic resources and the Internet; helping with setup for the delivery of computerbased courses; and downloading data files.

Of the 489 respondents $(67 \%)$ who did not request assistance in dealing with information technology, the two most fre- quently cited reasons were that they did not require assistance or were unaware that librarians provided it. Only 12 percent thought that librarians had insufficient ability or expertise.

\section{Research}

At the University of Manitoba, librarians have faculty status; thus research is both a right and a responsibility. Accordingly, the investigators were most eager to find out the level and type of research collaboration taking place between faculty and librarians. Not unexpectedly, when asked the preliminary question, Have you ever collaborated with a librarian on a research project? only $49(7 \%)$ of all respondents stated that they had (table 4). There were no significant differences among faculty groups.

It was not surprising to learn that the most common type of collaboration was that of performing a literature search, as chosen by 65 percent of those who responded in the affirmative. However, it was encouraging to observe that the next highest responses were gathering data $(26 \%)$ and working as a partner on a research project (22\%). Very low responses were recorded for cowriting a research proposal, creating or managing a database, analyzing data, and publishing the results. There were no significant differences among faculty groups for the various types of research collaboration.

Of the 684 respondents (93\%) who did not collaborate with a librarian on a research project, more than half claimed they had not thought of doing so, 23 percent responded that collaborative research is not part of the institutional culture, and another 20 percent said they had no time to develop collaborative research with a librarian. Despite the high rate of noncollaboration, however, it was gratifying to note that only 17 percent thought that librarians had insufficient ability and expertise or that it was inappropriate for a librarian to be part of a research project. The "other" category accounted for 19 percent of the responses. For the most part, these responses may be categorized into three main areas: there was no need 


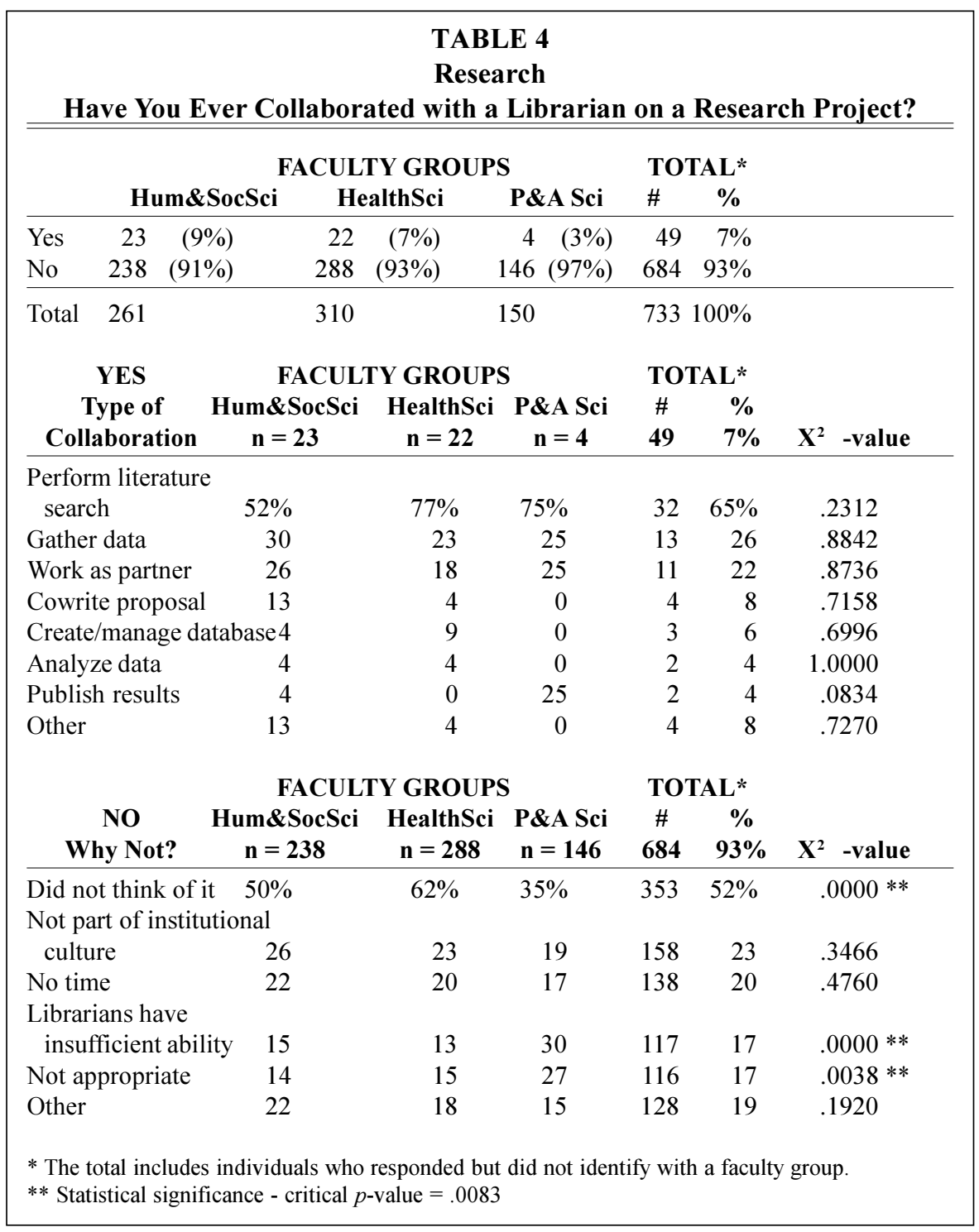

or opportunity for collaboration, the respondents were not involved in research or worked alone, or they wondered how librarians could be involved in collaborative research. Based on these results, it would seem that faculty do not have strong objections to engaging in collaborative research with librarians but are not conditioned to thinking about it. Therefore, librarians should seize the opportunity to approach the faculty and explore the possibilities of research partnerships.
The results by faculty group revealed very distinct differences between the humanities \& social sciences and the health sciences faculties as opposed to the pure $\&$ applied sciences faculty. The percentages of those who claimed they had not thought of collaborating with a librarian ranged from 35 percent of the pure \& applied sciences faculty to 50 percent of the humanities \& social sciences faculty and 62 percent of the health sciences respondents $(p<.0001)$. The pure \& applied sci- 
ences respondents also expressed a very strong opinion that research with faculty is not suitable for librarians. One third of that group did not think that librarians had sufficient ability or expertise $(p<$
.0001 ), and 27 percent considered it inappropriate for a librarian to be part of a research project $(p<.0038)$. These percentages are approximately twice those of the other two groups.

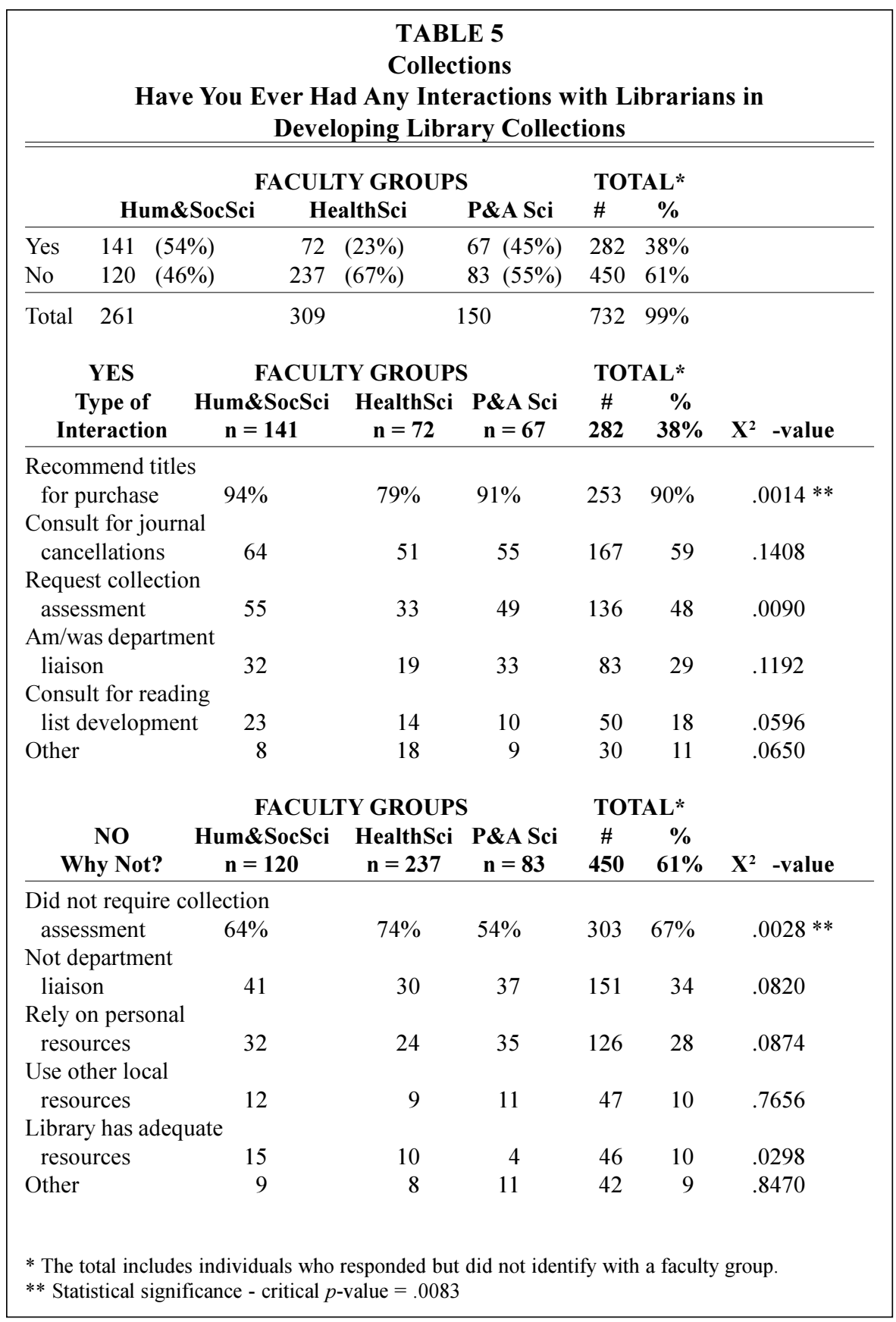




\section{Collections}

To the preliminary question, Have you ever had any interactions with librarians in developing library collections? 282 respondents $(38 \%)$ stated that they had done so (table 5). Overall, the health sciences faculty showed a much lower rate of interaction at 23 percent than the humanities \& social sciences faculty at 54 percent and the pure \& applied sciences faculty at 45 percent $(p<.0001)$.

Of the 282 who responded affirmatively, an overwhelming 90 percent said they had recommended titles for purchase, 59 percent indicated that they had consulted with librarians regarding journal cancellations, and 48 percent stated that they had requested collection assessments for course or program proposals. Of the 11 percent who chose to specify "other" types of interaction, some stated that the librarian helped to develop and enhance a collection and its access, collaborated with them on funding proposals, or reviewed a collection for accreditation purposes.

The humanities \& social sciences faculty reported the highest level of interaction with librarians for all the options offered, with the exception of the role as departmental library liaison. The percentages for the health sciences faculty were significantly lower than for the humanities \& social sciences and the pure \& applied sciences faculties for "recommended titles" ( $p=.0014)$ and borderline significant for "requested a collection assessment" ( $p=.0090)$. One likely reason for the lower response from the health sciences faculty is that the medical curriculum has changed from a didactic system-based approach to an integrated, case-based problem-solving format and therefore there are no structured courses in the traditional sense. Furthermore, the residency program in hospitals has clinical training without formal courses.

For the 450 respondents (61\%) who answered no to the preliminary question, the overwhelming reason given was that they had not required a collection assessment for a course or program. One third indicated that they had never acted as the departmental library liaison and 28 percent stated that they relied on personal resources. Nine percent of the respondents gave "other" reasons for not having had any contact with a librarian. Many claimed that they were unaware of the possibility or had not thought of asking. One recurring reason was the perception that no funds were available and so, resigned to this situation, faculty did not request materials for purchase. In the 1990s, the libraries underwent repeated serials cancellations and budget cutbacks, which contributed to low morale and, in turn, mitigated against collaboration. Felix T. Chu corroborated the authors' finding that less money equals less interaction: "Decreased budget gives fewer opportunities for informal communication and polarizes the perceived need for communication." ${ }^{\prime 13}$

In summary, figure 1 shows that the highest point of interaction between librarians and faculty was in the area of information services (88\%). Collections (38\%) and information technology (33\%) ranked second and third followed by teaching/instruction $(20 \%)$ and research $(7 \%)$. When the level of interaction by faculty group was examined for four of the five investigated areas (the level of response was too low to detect potential significance in research), the highest interaction was reported by the humanities \& social sciences faculty, followed by the health sciences and the pure \& applied sciences faculties. In the area of teaching/ instruction, the humanities \& social sciences faculty had twice the amount of interaction that faculty in the health sciences and the pure \& applied sciences did. On matters related to the collections, the humanities \& social sciences and pure \& applied sciences faculties had twice the interaction of the health sciences faculty. As for information technology, the results showed that interaction for the pure \& applied sciences faculty was approximately 50 percent less than for the other two faculty groups. These data concur with Rebecca Kellogg's statement: "Scien- 


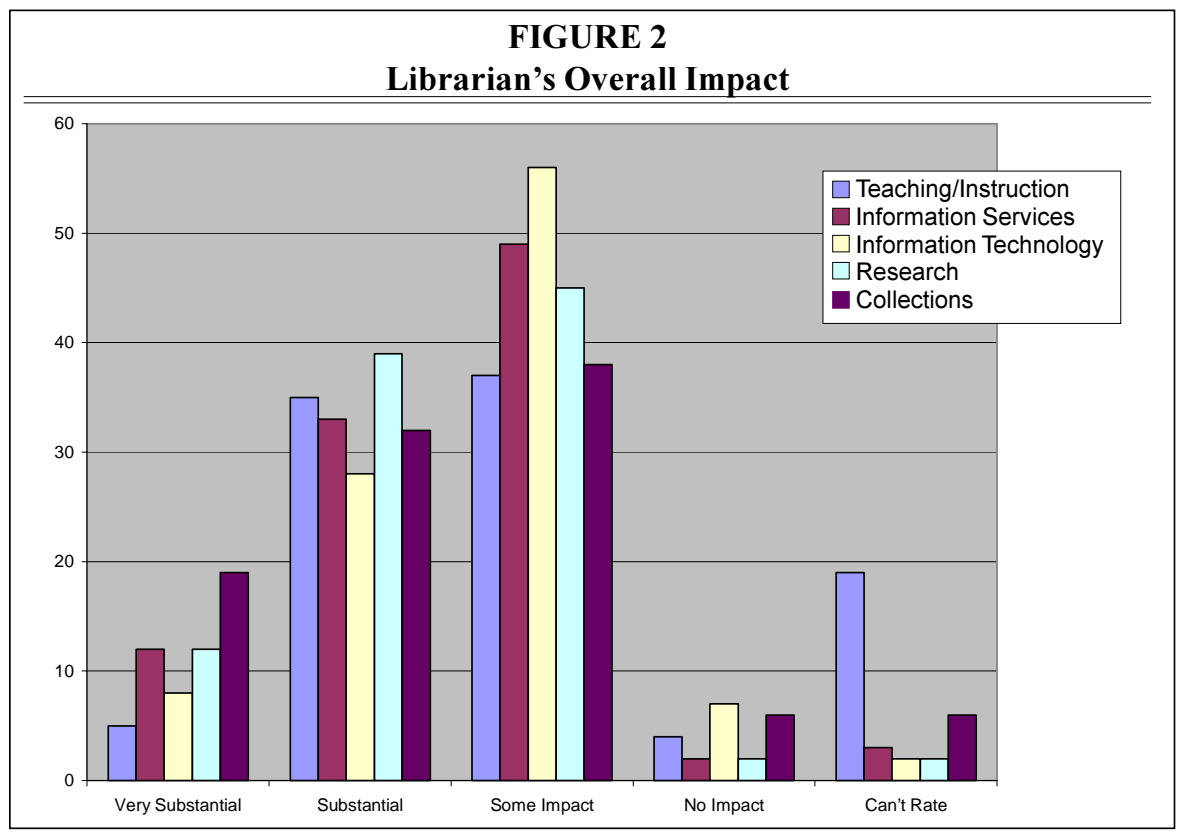

tists will have few interactions with librarians due to the nature of their work. Humanists will have had a much greater number of interactions, since the library essentially is their laboratory." 14

\section{Librarians' Impact}

Library literature abounds with anecdotal articles describing the value of librarianfaculty collaboration, but articles supported by empirical data are few. In the field of medical and special libraries, David N. King and Joanne G. Marshall have independently published research reporting the impact of library information services on clinical and corporate decision making. ${ }^{15-17}$ There do not appear to be any studies measuring the impact of librarians in the university setting.

To measure the impact of librarians' contributions in the five investigated areas, the authors asked those respondents who interacted with librarians to rate the impact. Combining responses to the "very substantial," "substantial," and "some impact" categories revealed that librarians have a very positive impact: research (96\%), information services (94\%), information technology $(91 \%)$, collections $(89 \%)$, and teaching/instruction $(77 \%)$.
However, the authors decided to focus their analysis on the combined responses to the "substantial" and "very substantial" impact categories, that is, on the faculty who had responded that librarians had a definite impact in the five areas of investigation. (See figure 2.)

\section{Teaching/Instruction}

In the area of teaching/instruction, 60 (or $40 \%$ ) of the 150 faculty who responded affirmatively to the preliminary question stated that librarians' teaching had a substantial or a very substantial impact on student performance, 56 (37\%) concluded that there was some impact, and only 6 (4\%) said there was no impact. Another 29 (19\%) responded that they could not rate this function. The low ratings for teaching/instruction compared to the other investigated areas are disappointing. Perhaps faculty view themselves as teaching core content, this being more critical to the educational process, and perceive librarians as providing instruction in accessing resources, this being more peripheral to the students' education. Other reasons for this low rating may be that faculty are unaware of how librarians can contribute or simply do not 
value librarian contributions. Or, as Larry R. Oberg, Mary Kay Schleiter and Michael Van Houten stated, faculty members believe librarians have "insufficient teaching and research and inadequate educational credentials." ${ }^{18}$ Whereas 42 percent of the humanities \& social sciences faculty and 41 percent of the health sciences faculty rated librarians' teaching as having a substantial or very substantial impact and the pure \& applied sciences faculty gave it a combined 24 percent rating, the groups are not statistically different at the five percent significance level in terms of percentages giving a substantial or very substantial rating.

Faculty who responded that librarians had an impact then were asked: What type of impact did the librarian's teaching have on student performance? Seventy-one percent of the respondents said that as a result of the instruction, students had fewer questions about how to find information, followed by 60 percent who said that students used a wider range of information sources and 42 percent who answered that students con-

TABLE 6 Type of Impact

\begin{tabular}{lrr}
\hline \hline & $\#$ & $\%$ \\
\hline Teaching/instruction & & \\
Students had fewer questions & 82 & 71 \\
Students used wider range of information & 69 & 60 \\
Better reviews of literature & 49 & 42 \\
Better bibliography & 39 & 34 \\
Students better able to evaluate information & 29 & 25 \\
Other & 7 & 6 \\
& & \\
Information services & & \\
Saved time & 524 & 86 \\
Identified appropriate resources & 344 & 57 \\
Expanded knowledge & 211 & 35 \\
Other & 43 & 7 \\
& & \\
Information technology & & \\
Solved technical problem & 112 & 50 \\
Made more efficient use of info technology & 110 & 50 \\
Taught use of electronic resources & 103 & 46 \\
Helped integrate new technology & 37 & 17 \\
Other & 12 & 5 \\
Research & & \\
Provided support & & \\
Provided additional expertise & 25 & 53 \\
Facilitated completion of project & 24 & 51 \\
Brought different perspective & 19 & 40 \\
Other & 15 & 32 \\
Collections & 2 & 4 \\
Developed better collections & & \\
Improved communication & 176 & 70 \\
Became aware of new resources & 126 & 50 \\
Gained understanding of scope & 90 & 36 \\
Learned collection was inadequate & 80 & 32 \\
Other & 53 & 21 \\
& 18 & 7 \\
\hline
\end{tabular}
ducted better reviews of the literature (table 6). These faculty responses were gratifying. However, it was disappointing to find out that only 25 percent of the respondents stated that students were better able to evaluate information sources. Today, when lifelong learning is necessary for all professions, it is essential that students know where to find information, look at a wide range of sources, and, most important, evaluate the information sources they have found.
Further analysis of the responses by faculty group suggests that faculty gave a higher rating to functions that could be considered more relevant to their field. The humanities \& social sciences faculty reported that "students used a wider range of information resources" at 69 percent as opposed to 58 percent for the health sciences faculty and 21 percent for the pure \& applied sciences faculty $(p=$ .0036). Because students in the humanities \& social sciences and the health sci- 
ences are usually required to access information sources beyond their textbooks and are required as a general rule to write more papers, it is natural that faculty would see this as a positive impact.

\section{Information Services}

To the question, Did the information service have an impact on your work? 45 percent responded that the information service had a substantial or a very substantial impact, 49 percent stated that it had some impact, and 2 percent said there was no impact. The results by faculty group show that there are statistically significant differences among them: the humanities \& social sciences and the health sciences faculties both reported ratings of 48 percent whereas the pure \& applied sciences faculty revealed a 34 percent rating $(p=.0092)$.

For 86 percent of the faculty who reported that the librarians' services had an impact, saving time was the most frequently cited result of requesting information services from librarians. Librarians also helped faculty identify more appropriate resources, at 57 percent (table 6 ). It was gratifying that 35 percent of the faculty stated that they expanded their knowledge of the subject as a result of interaction with a librarian.

All faculty groups reported that the main result of consulting a librarian was that it saved time. The only significant difference between the three groups was for the item "expanded my knowledge of the subject," which received a 42 percent response from the health sciences faculty, 33 percent from the humanities \& social sciences faculty, and 24 percent from the pure \& applied sciences faculty $(p=.0018)$.

\section{Information Technology}

When faculty were asked if librarians' assistance in dealing with information technology had an impact on their work, a combined 35 percent cited a substantial or a very substantial impact and 56 percent reported some impact. Only seven percent rated the assistance as having no impact. Although differences among the faculty groups were not statistically significant, it is interesting to note that pure $\&$ applied sciences was the only group to post a zero percent response for very substantial impact.

The most frequently cited effects of librarian assistance by those respondents who reported that it had an impact were to solve technical problems and to make faculty more efficient in using information technology, both at 50 percent, and to teach faculty how to use electronic resources, at 46 percent (table 6). Helping to integrate new technology into research or teaching was less cited at 17 percent, concurring with the results reported earlier in the study showing that the lowest points of interaction between librarians and faculty were in teaching/instruction and research.

\section{Research}

The ratings in the area of research collaboration came as a pleasant surprise. Although the level of interaction for research was low in comparison to other areas (only 49 , or $7 \%$, of all respondents claimed to have worked with a librarian on a research project), the results demonstrate that where there is collaboration with librarians, the experience is extremely positive. Fifty-one percent of the forty-nine respondents claimed that the librarian's involvement in research had a substantial or a very substantial impact on the project, 45 percent reported that it had some impact, and only 2 percent, no impact.

More than half the respondents who considered that the librarian had an impact reported that the librarian's involvement had provided additional expertise and skills and that the librarian had provided support for the project. Forty percent believed that the librarian had facilitated the completion of a research project, and 32 percent indicated that the librarian had brought a different perspective. Given that there were few respondents in all three groups, there was insufficient statistical power to determine whether the faculty groups differed in proportions of positive responses. 


\section{Collections}

Collection development being a core function of librarianship, it is disconcerting to observe that only 51 percent of the respondents who interacted with librarians reported that their contact had a very substantial or a substantial impact. Is this response a reflection on the effectiveness of librarians or the fact that librarians may have had limited control over financial resources at the time? Thirty-eight percent claimed that their interaction had some impact whereas six percent indicated no impact. The humanities \& social sciences faculty evaluated their interaction with librarians most favorably, with 58 percent rating their experience as substantial or very substantial, followed by 46 percent of the health sciences faculty and 40 percent of the pure \& applied sciences faculty $(p=.0288)$.

Seventy percent of the respondents who reported that their interaction with librarians had an impact claimed that the interaction led to the development of better collections (table 6). Fifty percent cited improved communication between de- partment and library. An almost equal number reported that they had gained a better understanding of the scope of collections management (32\%) and had become aware of new resources in the field $(36 \%)$. Only 21 percent said that they had learned that the collection was inadequate for a proposed course or program.

\section{Librarian's Role}

A more general set of questions was designed to rate the librarian's role in the university community. All respondents were invited to respond whether they had previously interacted with librarians.

When combining the results to the "very important" and "important" options, the faculty rated the librarian's role in the following descending order of importance: information services $(84 \%)$, collections $(80 \%)$, information technology $(69 \%)$, research $(60 \%)$, and teaching/instruction (50\%). The "somewhat important" rating yielded the following results: teaching/instruction (31\%), research $(24 \%)$, information technology (17\%), information services $(8 \%)$, and collections

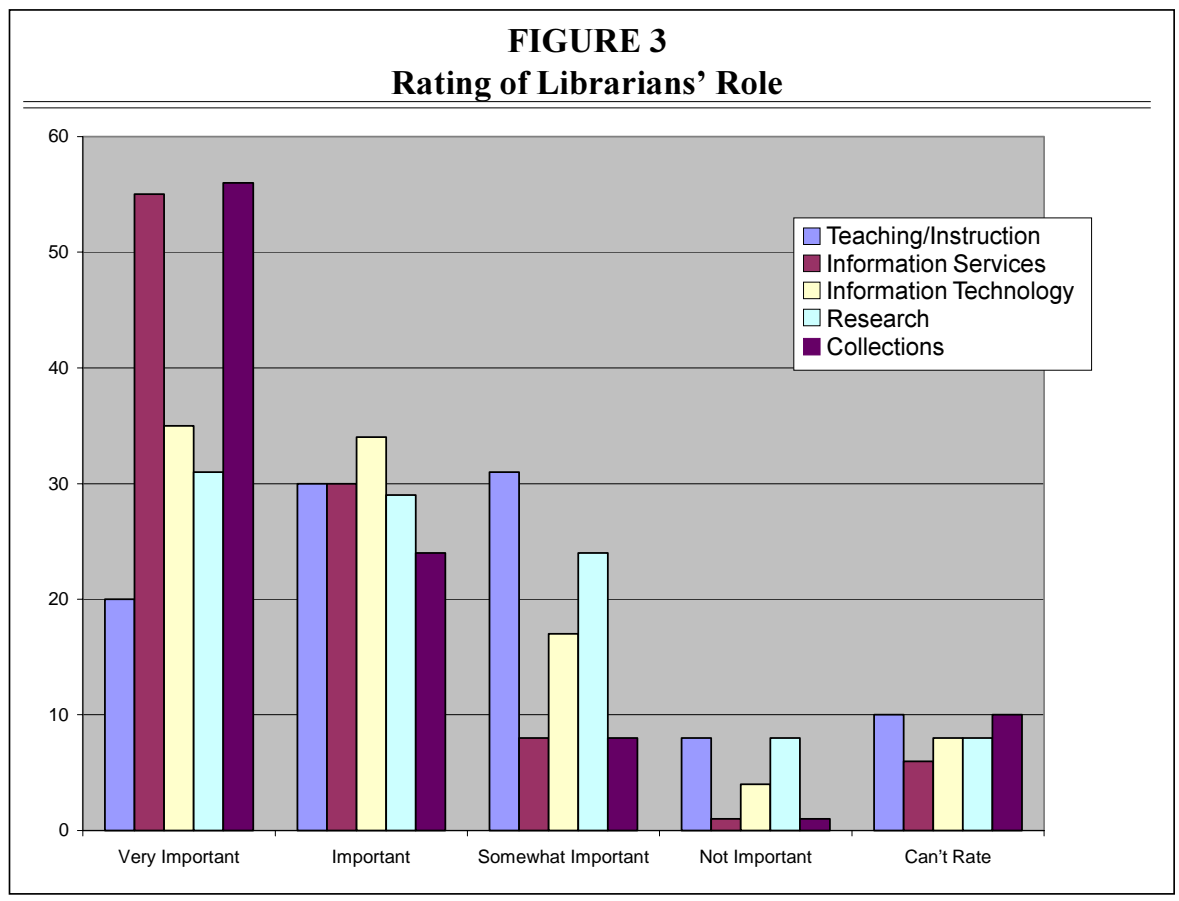


$(8 \%)$. The response rate for "not important" ranged from a low one to eight percent in the respective areas. These positive results suggest that librarians have generally been accepted by the rest of the faculty as academic colleagues with unique competencies. (See figure 3.)

Not unexpectedly, information services and collections, the areas most traditionally associated with librarianship, were ranked the highest. However, information technology and research received a comparatively high rating considering that these are not areas that faculty usually

\section{One $f$ the main purposes of this study identify possible future roles for librarians that will enhance the faculty-librarian partnership.}

identify with librarians and, as the survey showed, are areas where interaction is low. Teaching/instruction received the lowest rating. This response may be the result of the faculty's perception that teaching by librarians is an intrusion into their domain. Alternatively, faculty may not have a clear understanding of the librarian's teaching role or appreciate that "after graduation, students will not learn from lectures and reserve books. They need to be prepared for this future now by being taught how to gather, evaluate, and utilize sources on their own."19

When analyzing the "important" and "very important" data by faculty group, the results for teaching/instruction showed no significant differences among the three groups. There are variations in responses to information services, where 87 percent of the humanities \& social sciences faculty, 85 percent of the health sciences faculty, and 80 percent of the pure \& applied sciences faculty reported that the librarians' role was important or very important $(p<.0001)$, and to information technology where the health sciences faculty reported a 75 percent rating, the humanities \& social sciences faculty a 70 percent rating, and the pure \& applied sciences faculty a 56 percent rating $(p<$ $.0001)$. A wider variation exists in the area of research. Humanities \& social sciences faculty rated the librarians' research role at 72 percent whereas the health sciences and the pure \& applied sciences faculties rated it at 53 and 52 percent, respectively $(p<.0001)$. A similar pattern emerged for collections, where the humanities \& social sciences faculty rated the librarians' collections role at 91 percent and the health sciences and the pure \& applied sciences faculties rated it at 74 and 76 percent, respectively $(p=.001)$. No doubt, these responses can be explained by the nature of the disciplines and their different needs.

\section{Expanded Roles}

One of the main purposes of this study was to identify possible future roles for librarians that will enhance the facultylibrarian partnership. For each area of investigation, all faculty were asked how librarians could contribute to their endeavors.

In the area of teaching/instruction, the highest response was for assisting faculty with their information retrieval skills so that they could better teach students (48\%). This was followed by 44 percent who wanted librarians to help integrate technology into the curriculum and then by 30 percent who wanted librarians to assist with interactive instruction.

Having librarians teach a full course on information literacy was selected by only 17 percent of the faculty. Given that many academic libraries are hiring information literacy librarians and that librarians are focusing their attention on developing information literacy courses, the question remains: Will faculty support these efforts, or will these endeavors be ignored? Librarians should heed Patricia Iannuzzi, who pointed out that in order to succeed, information literacy must be part of the institutional culture. She encouraged librarians "to play a role in suggesting appropriate language" for the administration. When information literacy becomes part of the institutional culture, it will lead to a greater acceptance of the courses that librarians are offering. ${ }^{20}$ 
In addition, librarians must be more proactive in order to establish the importance of their contribution to information literacy. Marian C. Winner stated that "Librarians must expand their teaching role and must demonstrate to faculty that they have the background and knowledge to be useful partners for faculty and curriculum planning." 21

The comments received in the "other" category revealed that faculty wanted librarians to develop a self-directed learning package, show students how to think outside the Web, teach students how to use the Internet effectively, help students evaluate Internet resources, and assist in developing a reference database.

In the area of information services, approximately half the respondents stated that "identification of key Internet sites" would be useful. Perhaps faculty are not as proficient in their use of the Internet and recognize that librarians have skills in this area. Librarians should not only play up their skills at finding Internet sites, but also their ability to evaluate them, thereby saving the faculty member a lot of time and effort. About half the respondents wanted a "complete package of information." Although this service may seem obvious, most libraries would find it difficult to consider offering it because of a lack of resources. However, if this service is that important to faculty, libraries should find ways to redirect resources by shifting staff from areas where the workload is declining (e.g., circulation because more material is becoming available electronically). This would enhance the librarians' relationship with the faculty without entailing the addition of human resources. "Other" responses included: any service that could expedite locating and retrieving literature not held by local libraries, the use of databases, and information on new resources as they become available. Jordan M. Scepanski has supported an expanded role for librarians in the area of information services by suggesting that they interpret and evaluate the information they find: "The librarian of the future will be a refiner of information, not a passive provider of it-and, thereby, will become an active and accepted partner in the educational process." 22

The most desired service (43\%) in the area of information technology is to "provide assistance with retrieving an electronic document." This points to the fact that finding electronic documents can be a very complicated process. Using proxy servers, being familiar with database idiosyncrasies, and understanding the complexities of online and linking systems all make accessing electronic documents problematic. Librarians should work toward facilitating the retrieval of electronic documents for their users. A comparatively low 20 percent thought that the librarian could help develop institutional Web sites. This recognizes the expertise of librarians and places them outside the traditional library walls.

Among the most interesting and innovative of the "other" comments were: develop Internet-based delivery of course and lecture notes, integrate reference software with the library system, and teach faculty how to use multimedia software more appropriately. Librarians have been using information technology since the mid-1970s when computerized literature searching was introduced. In the intervening years, they have integrated many technological innovations into library service and, as a result, have developed an expertise they can use to help faculty integrate technology into their teaching and research. Scepanski forecasted that the librarians of the future will use their expertise to "be the academic unit's expert on database construction and organization and on sources of information both on and off campus. [They] will create databases taken from a variety of sources and tailored to the particular interests and specializations of the department." 23

When asked in what capacity they would consider collaborating with a librarian on a research project, 66 percent of faculty cited the traditional function of performing a literature search. Thirtyeight percent selected "creating or man- 
aging a database" and 37 percent "gathering data." Although "working as a partner on a research project," "analyzing data," and "publishing the results" yielded low percentages in comparison with the other responses, the fact that between 23 and 26 percent saw these roles as valid for librarians is very encouraging. Librarians should see these activities as areas of opportunity for enhanced collaboration with faculty. Some of the "other" types of collaboration included retrieving documents, seeking publishing possibilities, editing the text, preparing a major review article or a textbook, drafting literature reviews, and doing metaanalysis research. Many of the functions that faculty appear to value are ones that Robert Grover and Martha L. Hale would most likely consider to be at a "more proactive or assertive level which will support and augment the work of the researcher." ${ }^{24}$ In their article, "The Role of the Librarian in Faculty Research", they "have proposed a model for library service which interjects the librarian directly into the research process." 25

\section{Librarians should assume that faculty know what librarians do.}

In terms of collection development, faculty were most in favor of librarians "providing access to resources on the Internet" and "developing agreements with other institutions to share resources," both rated at 57 percent. A lower 40 percent indicated that librarians should investigate alternative funding opportunities. Twenty-six percent suggested that librarians be members of faculty/departmental curriculum committees and 22 percent that they participate in the development of courses.

When analyzing the results by faculty group, there are many functions where there are no significant differences among groups. However, the pure \& applied sciences faculty rated the following functions significantly lower $(p<.05)$ than the other two groups: "helping to integrate technology into the curriculum," "assist- ing with interactive instruction," "teaching a full course on information literacy," "identification of key Internet sites in my field," " teach me how to use software," "develop or manage databases," "resolve technical problems," "cowriting the research proposal," "creating or managing a database," "working as a partner on a research project," "gathering data," "analyzing data," "publishing the results," "provide access to resources on the Internet," and "participate in the development of courses."

\section{Conclusion}

At the opening of this article, the authors referred to their 1985 study on faculty perceptions of librarians at the University of Manitoba. Although, at that time, the results indicated a low acceptance of librarians as full-fledged academic colleagues, this recent study demonstrates that in the intervening years there appears to have been an important shift in faculty attitudes and expectations. In each of the areas investigated, the results clearly show that when faculty interact with librarians, librarians have a very positive and considerable impact on both faculty and students. In addition, the responses indicate that faculty would be more receptive to collaborating with librarians at a higher level of interaction than currently experienced. This view is reinforced by the finding that relatively few faculty cited insufficient ability or lack of expertise as reasons for not interacting with librarians.

Although the results were gratifying, they also showed that a large number of faculty were unaware of librarians' capabilities. A number of comments included at the end of the survey emphasized this point. Some examples include: "Thank you for bringing the role of librarians to my attention. Your survey has caused me to consider how librarians can be part of my teaching and my research." "I was not aware of the full range of services available from university librarians. I will consider more consultation in the future." "I guess I am not very educated in what li- 
brarians can do." "Joint research prospects are intriguing. Perhaps they don't have high profile because we're not pausing to reflect on the possibilities." And lastly, "I found it very interesting and enlightening to complete this survey. I would like to get more information on the services that can be provided and the potential for research collaboration." Librarians should not assume that faculty know what librarians do. Rather, they should make every effort to interact with faculty in order to build good relationships. As a result, the faculty may become more aware of librarians' skills and abilities. As Wade R. Kotter stated: "If good relations are consistently cultivated, many of the problems with collaboration will disappear; good friends are less likely to fail at collaboration than total strangers." 26

Another concern is the fact that the faculty in the pure \& applied sciences consistently reported less interaction with librarians and that this interaction has less impact. They were most likely to think that librarians had insufficient ability or expertise and, in comparison with the other two groups, they considered librar- ians' contributions to the academic enterprise to be less important. This is no doubt attributable to the nature of the disciplines and to the way research is conducted. Many academic librarians commonly share this belief, and this study confirms the attitudes of pure and applied scientists. Librarians working in the field of the pure and applied sciences should investigate the faculty's attitudes further and determine whether it would be beneficial to make greater efforts to engage the scientists and how they can best promote their expertise to them.

This study has demonstrated that established relationships provide a good foundation for ongoing collaboration. The study results show that the faculty respondents at the University of Manitoba highly rate the librarians' role in the university and endorse a greater level of interaction. These ratings and the expanded roles that faculty would like librarians to undertake reflect the high expectations most faculty have of librarians and the integral role they see librarians playing in the educational process. Librarians must now meet the challenge.

\section{Notes}

1. Gaby Divay, Ada M. Ducas, and Nicole Michaud-Oystryk, "Faculty Perceptions of Librarians at the University of Manitoba," College $\mathcal{E}$ Research Libraries 48 (Jan. 1987): 27-35.

2. Ibid., 27.

3. Sheila D. Creth, "A Changing Profession: Central Roles for Academic Librarians," Advances in Librarianship 19 (1995): 85-98.

4. Carla Stoffle, Barbara Allen, and Janet Fore, "Reinventing Academic Libraries and Librarianship," College \& Research Libraries News 61 (Nov. 2000): 895.

5. Doug Cook, "Creating Connections: A Review of the Literature," in The Collaborative Imperative: Librarians and Faculty Working Together in the Information Universe, ed. Dick Raspa and Dane Ward (Chicago: Association of Research Libraries, 2000), 19.

6. Mary Lynn Rice-Lively and J. Drew Racine, "The Role of Academic Librarians in the Era of Information Technology," Journal of Academic Librarianship 23 (Jan. 1997): 31-41. $26-30$.

7. Evan St. Lifer, “Net Work: New Roles, Same Mission," Library Journal 121 (Nov. 15, 1996):

8. Donald H. Dilmore, "Librarian/Faculty Interaction at Nine New England Colleges," College $\mathcal{E}$ Research Libraries 57 (May 1996): 274-84.

9. Devin Feldman and Susan Sciammarella, "Both Sides of the Looking Glass: Librarian and Teaching Faculty Perceptions of Librarianship at Six Community Colleges," College $\mathcal{E}$ Research Libraries 61 (Nov. 2000): 491-98.

10. Bee Gallegos and Thomas Wright, "Collaborations in the Field: Examples from a Survey," in The Collaborative Imperative: Librarians and Faculty Working Together in the Information Universe, ed. Dick Raspa and Dane Ward (Chicago: Association of Research Libraries, 2000), 97-113.

11. Anita Cannon, "Faculty Survey on Library Research Instruction," $R Q 33$ (summer 1994): $524-41$.

12. For information on the R statistical software, see http://www.r-project.org. 
13. Felix T. Chu, "Librarian-Faculty Relations in Collection Development," Journal of Academic Librarianship 23 (Jan. 1997): 18.

14. Rebecca Kellogg, "Faculty Members and Academic Librarians: Distinctive Differences," College E Research Libraries News 48 (Nov. 1987): 604.

15. David N. King, "The Contribution of Hospital Library Information Services to Clinical Care: A Study of Eight Hospitals," Bulletin of the Medical Library Association 75 (Oct. 1987): 291301.

16. Joanne G. Marshall, "The Impact of the Hospital Library on Clinical Decision-Making: The Rochester Study," Bulletin of the Medical Library Association 80 (Apr. 1992): 169-78.

17. - - , The Impact of the Special Library on Corporate Decision-Making (Washington, D.C.: Special Libraries Association, 1993).

18. Larry R. Oberg, Mary Kay Schleiter, and Michael Van Houten, "Faculty Perceptions of Librarians at Albion College: Status, Role, Contribution, and Contacts," College E Research Libraries 50 (Mar. 1989): 223.

19. Barbara B. Moran, "Library/Classroom Partnerships for the 1990s," College E Research Libraries News 51 (June 1990): 513.

20. Patricia Iannuzzi, "Faculty Development and Information Literacy: Establishing Campus Partnerships," Faculty Development and Information Literacy 26 (fall/winter 1998): 98.

21. Marian C. Winner, "Librarians as Partners in the Classroom: An Increasing Imperative," Reference Services Review 26 (spring 1998): 26.

22. Jordan M. Scepanski, "Forecasting, Forestalling, Fashioning: The Future of Academic Libraries and Librarians," in Academic Libraries: Their Rationale and Role in American Higher Education (Westport, Conn.: Greenwood Pr., 1995), 171.

23. Ibid., 172.

24. Robert Grover and Martha L. Hale, "The Role of the Librarian in Faculty Research," College $\mathcal{E}$ Research Libraries 49 (Jan. 1988): 10.

25. Ibid., 14.

26. Wade R. Kotter, "Bridging the Great Divide: Improving Relations between Librarians and Classroom Faculty," Journal of Academic Librarianship 25 (July 1999): 295. 